\title{
LA VOZ DE CARLOTA DE MÉXICO EN EL TESTIMONIO DEL PERSONAJE DE AUXILIO LACOUTURE EN LOS DETECTIVES SALVAJES DE ROBERTO BOLAÑO
}

\author{
Francisco Javier Gil Jacinto \\ Universidad de Sevilla \\ masefo@yahoo.es
}

\begin{abstract}
RESUMEN: En este trabajo se analizan las correspondencias estilisticas y semánticas entre el testimonio del personaje de Auxilio Lacouture en el capitulo cuarto de la segunda parte de Los detectives salvajes de la novela del escritor chileno Roberto Bolaño y ciertos pasajes de la del mexicano Fernando del Paso, Noticias del Imperio, en los que recrea el discurso de la emperatriz Carlota de México. Para ello se ha partido de un concepto amplio de la noción de intertextualidad de acuerdo con las aportaciones de algunos de los más reconocidos expertos en la materia, pero sin desatender otros recursos de la literatura postmoderna, que muestran las correlaciones existentes entre los textos analizados.
\end{abstract}

PALABRAS CLAVE: Auxilio Lacouture, Bolaño, Carlota de México, Fernando del Paso, intertextualidad.

\section{THE VOICE OF CARLOTA DE MÉXICO IN THE TESTIMONY OF THE CHARACTER OF AUXILIO LACOUTURE IN LOS DETECTIVES SALVAJES BY ROBERTO BOLAÑO}

ABSTRACT: This work analyses the stylistic and semantic correspondence between the speech of Auxilio Lacouture in the fourth chapter of part two of the novel Los detectives salvajes by the Chilean writer Roberto Bolaño and some passages from the Mexican Fernando del Paso's Noticias del Imperio in the speech of Carlota of México. The starting point for this essay is a broad concept of the notion of intertextuality, according to some relevant experts on the subject, without neglecting other resources of postmodern literature, which show the correlations between the analysed texts.

KEYWORDS: Auxilio Lacouture, Bolaño, Carlota de México, Fernando del Paso, intertextuality. 


\title{
LA VOIX DE CARLOTA DU MEXIQUE DANS LE TÉMOIGNAGE DU PERSONNAGE DE AUXILIO LACOUTURE DANS LOS DETECTIVES SALVAJES DE ROBERTO BOLAÑO
}

\author{
RÉSUMÉ : Cet article analyse la correspondance stylistique et sémantique \\ entre le discours d'Auxilio Lacouture dans le quatrième chapitre de la deuxième \\ partie du roman Los détectives salvajes de l'écrivain chilien Roberto Bolaño \\ et certains passages des Noticias del Imperio du mexicain Fernando del Paso \\ dans le discours de Carlota du Mexique. Le point de départ de cet essai est un \\ concept large de la notion d'intertextualité, selon certains des plus éminents \\ experts, sans négliger d'autres ressources de la littérature postmoderne, qui \\ montrent les corrélations entre les textes analysés. \\ MOTS CLÉS : Auxilio Lacouture, Bolaño, Carlota de México, Fernando del \\ Paso, intertextualité.
}

Recibido: 31/08/1010. Aceptado: 18/11/2020

\section{Introducción: la novela de un escritor mexicano y la novela de un escritor en México}

En 1986, el autor mexicano Fernando del Paso termina de escribir en París Noticias del Imperio, una extensa novela que había comenzado en Londres diez años antes. En su breve prefacio se cuenta cómo, en 1861, el presidente de México, Benito Juárez, suspende los pagos de su deuda externa, una medida a la que Napoleón III, por entonces emperador de Francia, responde con el envío de un ejército de ocupación y creando una monarquía a cuyo frente coloca a un príncipe de la casa de Habsburgo, Maximiliano de Austria, que desembarca en 1864 en Veracruz acompañado de su esposa, la princesa Carlota de Bélgica.

De los veintitrés capítulos que conforman el total de la obra, los números pares -once en total- narran el hecho histórico al que se refiere su autor y tienen su propio título. Por contra, los impares se titulan todos "Castillo de Bouchout 1927" en alusión a la muerte de Carlota en dicho castillo tras sesenta años de enclaustramiento. Es también el sitio donde la emperatriz, en su locura, recibe al mensajero que le trae noticias del mundo exterior y desde donde, a su vez, se dirige a su esposo para compartir con él una crónica, en la que se mezclan pasado 
y presente, a través de la cual va repasando los hechos más relevantes de su vida, que lo son, además, de parte de la historia de México.

Una década más tarde de la publicación de Noticias del Imperio, el chileno Roberto Bolaño es galardonado en 1998 con el premio Herralde de novela por Los detectives salvajes. La novela consta de tres partes: la primera y la tercera transcurren en el D. F. y en el desierto de Sonora, respectivamente, y son el diario del personaje Juan García Madero, un estudiante de Derecho que termina por abandonar la universidad para militar en las filas del realismo visceral, un movimiento literario liderado por Arturo Belano y Ulises Lima, mientras que la segunda parte está conformada por los testimonios de cincuenta y dos personajes en los que se recogen sus encuentros con Belano y Lima.

La tarea de hallar algún punto en común entre estas dos larguísimas novelas -622 páginas Los detectives salvajes y 1047 Noticias del Imperio- no parece que vaya a ser difícil; por lo que su extensión, junto con el hecho de que las acciones de ambas transcurren principalmente en México, pero también en otros lugares de Europa, así como el elevado número de personajes que intervienen en sus tramas podrían ser citados ya como algunos de los elementos convergentes entre ambas obras. Pero antes de empezar a analizar las conexiones entre una y otra dentro del ámbito estrictamente literario, podríamos comenzar por señalar algunas correspondencias biográficas de sus autores: los dos son hispanoamericanos, poetas, cultivadores asimismo del subgénero policíaco y postulantes ambos en su día a la beca Guggenheim con que la fundación, dentro de su programa para Latinoamérica, subsidia a un escritor hispanohablante, aunque bien es cierto que esta solo le fue concedida al mexicano Fernando del Paso para que realizara su proyecto de novelar la vida de Carlota de Bélgica y del Segundo Imperio de México, pues la petición que realizó Bolaño en noviembre de 1996 para escribir Los detectives salvajes no fue aceptada (Leal 2019: 52-53). Este revés no fue óbice para que, aun sin contar con esta ayuda, el escritor chileno pudiera concluir su novela, cuyo capítulo cuarto de la segunda parte, un relato en primera persona de uno de los personajes llamado Auxilio Lacouture narrando su relación con Belano, remite al discurso del personaje de la emperatriz Carlota al comienzo de Noticias del Imperio:

Yo soy la madre de la poesía mexicana. Yo conozco a todos los poetas y todos los poetas me conocen a mí. Yo conocí a Arturo Belano cuando él tenía dieciséis años y era un niño tímido y no sabía beber. Yo soy uruguaya, de Montevideo, pero un día llegué a México sin saber muy bien por qué, ni a qué, ni cómo, ni cuándo. Yo llegué a México Distrito Federal en el 
año 1967 o tal vez en el año 1965 o 1962. Yo ya no me acuerdo ni de las fechas ni de los peregrinajes, lo único que sé es que llegué a México y ya no me volví a marchar. Yo llegué a México cuando aún estaba vivo León Felipe [...]. (Bolaño 1998: 190)

Yo soy María Carlota de Bélgica, Emperatriz de México y de América. Yo soy María Carlota Amalia, prima de la Reina Victoria de Inglaterra, Gran Maestre de la Cruz de San Carlos y Virreina de las provincias del Lombardo Véneto acogidas por la piedad y la clemencia austríacas bajo las alas del águila bicéfala de la Casa de Habsburgo. Yo soy María Carlota Amalia Victoria, hija de Leopoldo Príncipe de Sajonia-Coburgo y el Rey de Bélgica. Yo soy María Carlota Amalia Victoria Clementina, hija de Luisa María de Orleáns, la reina santa de los ojos azules y la nariz borbona que murió de consunción y de tristeza por el exilio y la muerte de Luis Felipe, [...]. (Del Paso 1994: 9)

\section{La intertextualidad, un enfoque metodológico para leer a Bolaño releyendo a Del Paso}

La noción de intertextualidad como marca característica del postmodernismo literario, del que Los detectives salvajes se considera una de sus "novelas paradigmáticas" (De Mora Valcárcel 2015: 34), proporciona una perspectiva metodológica desde la que abordar el grado de concomitancias entre los textos de Bolaño y de Del Paso. Pero, como apuntan De Gómez González y Castillo Perilla, desde la aparición de la palabra intertextualité en una serie de artículos publicados entre 1966 y 1967 por Julia Kristeva, el término ha ido tomando por la crítica diversas direcciones (1998: 31-32). Tal falta de acuerdo sobre las distintas acepciones de la voz intertextual está perfectamente sintetizada en un artículo de Montes Doncel y Rebollo Ávalos (2006), cuyo subtítulo "El largo periplo de un término teórico" resulta harto elocuente. Por lo tanto, en este trabajo, con el fin de evitar el debate acerca de las posturas adoptadas por unos y otros con respecto a la noción de intertextualidad, se manejará una concepción amplia de su significado en la línea de quienes, según Martínez Fernández, la contemplan "como una propiedad o cualidad de todo texto, concebido como un tejido de textos" y que "remite siempre a otros textos, en una realización asumidora, transformadora o transgresora" (2001: 10-11).

Es, pues, con este sentido amplio del concepto de intertextualidad con el que se abordará aquí el estudio de la relación entre el testimonio de Auxilio Lacouture en el capítulo cuarto de la segunda parte de Los detectives salvajes y el monólogo de Carlota de México con el que se abre Memorias del Imperio, 
que, aunque se trate de fragmentos de dos novelas diferentes, pueden llegar, según para qué lectores, a resonar de manera superpuesta. La imagen de ambos personajes recitando al unísono, en principio, al menos en lo que a su estructura sintáctica se refiere, un mismo texto concita la idea de "copresencia entre dos o más textos" contenida en la definición de intertextualidad de Genette (1989: 10), de quien interesa para este trabajo su concepto de imitación referido a las operaciones de transformación de un texto derivado de otro preexistente (1989: 14). Esta misma línea de investigación la encontramos en Nogales Baena, quien recurre a dichas nociones de imitaciones y transformaciones en el sentido que los usa Genette para hacer una lectura intertextual de los primeros cuentos del escritor mexicano Sergio Pitol, "considerando aquello que tradicionalmente se ha leído como 'influencia literaria' desde un punto de vista activo y creativo por parte del escritor” (2017: 142).

Con respecto a la existencia y alcance de las transformaciones de las que habla Genette llevadas a cabo por Bolaño en Los detectives salvajes, De Mora Valcárcel señala que uno de los rasgos característicos del autor es la tendencia a integrar en sus novelas una selección de otros autores a los que admira y con los que simpatiza y a referirse con desdén a aquellos que no le interesan; por tanto, para Bolaño, "la intertextualidad es una forma de reconocimiento a otros escritores - marcada, unas veces, y no marcada, otrasque recorre gran parte del tejido narrativo, ya que se trata de una novela fundamentalmente dialógica" (De Mora Valcárcel 2015: 34). La integración en Los detectives salvajes del discurso de Carlota de México a través del personaje de Auxilio Lacouture debe entenderse, pues, como un caso de intertextualidad no marcada, dado que Bolaño no hace ninguna mención en el texto a Noticias del Imperio, mientras que, sin embargo, realiza una clara alusión al título de la novela del escritor mexicano Carlos Fuentes, La región más transparente (1958):

\footnotetext{
Vivir en el DF es fácil, como todo el mundo sabe o cree o se imagina, pero es fácil si tienes algo de dinero o una beca o un trabajo y yo no tenía nada, el largo viaje hasta la región más transparente me había vaciado de muchas cosas, entre ellas la energía necesaria para trabajar según qué cosas. (Bolaño 1998: 191)
}

No es momento de dilucidar aquí si la referencia más o menos directa al título de una de las novelas y la omisión de la que, precisamente, se correspondería con el texto A o hipertexto - de acuerdo con algunas de las denominaciones 
empleadas por Genette (1989: 10) para lo que tradicionalmente se ha venido conociendo como fuente- puede estar relacionada con la admiración o el denuesto de Bolaño a la hora de realizar la selección de los autores que, como parte del ejercicio intertextual, incorpora en sus novelas. Igualmente, podría tratarse de una llamada de atención de cómo algunos autores mexicanos contaron con el dinero de sus familias o con la ayuda de becas -como la de la fundación Guggenheim en el caso de Del Paso- sin pasar por apuros económicos mientras escribían sus obras.

No obstante, fuera del texto objeto de análisis sí encontramos dos referencias directas al autor de Noticias del Imperio, pero esta vez no en boca de Auxilio Lacouture, sino sacadas del testimonio de Luis Sebastián Rosado, otro de los poetas que tuvo contacto con Arturo Belano. En la primera de estas referencias, el nombre de Fernando del Paso aparece en una descripción que hace este personaje del ambiente de Priapo's, una discoteca que visitó con los escritores viscerrealistas, en la que:

El mobiliario y los especímenes humanos que adornaban su interior parecían extraídos arbitrariamente de El Periquito Sarniento, de Lizardi, de Los de abajo, de Mariano Azuela, de José Trigo, de Del Paso, de las peores novelas de la Onda, y del peor cine prostibulario de los años cincuenta. (Bolaño 1998: 154)

Más tarde se volverá a referir a él hablando de la marcha de Piel Divina, otro de los poetas del grupo:

También se llevó algo de dinero, no mucho, el que solía dejar en un cajón de mi escritorio por si tenía alguna eventualidad mientras yo no estaba, y un pantalón, varias camisas y una novela de Fernando del Paso. (Bolaño 1998: 353)

En la cita anterior, su autor no especifica el título de la novela de Fernando del Paso, y en la previa a esta, la que se nombra es José Trigo; por lo que, hasta donde se ha podido comprobar, no hay ninguna mención explícita en Los detectives salvajes a Noticias del Imperio. Es decir, nos encontramos ante un caso de derivación de un texto a otro en el que, como explica Genette, en el texto B no se habla en absoluto del texto A, pero sin el cual no podría existir, y al que, "en consecuencia, evoca más o menos explícitamente, sin necesariamente hablar de él o citarlo" (1989: 14). Ahora bien, el verbo evocar puede resultar demasiado impreciso y difícil de cuantificar metodológicamente. Así, por ejemplo, si 
volvemos a la primera cita tomada del testimonio de Auxilio Lacouture, en la que se queja de las dificultades que supone vivir en la ciudad de México para una expatriada uruguaya sin trabajo estable, y que empieza "Vivir en el DF es fácil, como todo el mundo sabe" (vide supra), para un lector buen conocedor de Noticias del Imperio este fragmento puede evocar el pasaje en el que Carlota, como si le diera la réplica, se lamenta de lo difícil que es también para ella, como reina expatriada, vivir en el exilio: "Morir, claro, es más fácil que seguir vivo. Estar muerto y cubierto de gloria es mejor que estar viva y sepultada en el olvido" (Del Paso 1994: 248).

La pregunta que cabría hacerse es la de cuántos lectores capaces de poner a dialogar ambos textos son necesarios para considerar que uno se deriva necesariamente del otro. Si abordamos la cuestión desde la perspectiva de la teoría de la recepción, con uno solo sería suficiente, pues, tal y como entiende a Riffaterre (1979) De Vicente-Yagüe, "la competencia literaria del lector es fundamental en la interpretación del texto, pues es el lector, a través del proceso de la lectura, el que debe actualizar y reescribir lo reflejado por el texto" (2013: 251).

En cualquier caso, la lectura convergente de dos textos, al menos de los estudiados en este trabajo, no debe suponer la interpretación literal de "la muerte del autor" anunciada por Barthes, sino más bien de un acto de ocultamiento en el que "el Autor [sic mayúscula] se empequeñece como una estatuilla al fondo de la escena literaria" (1994: 68). Habría, por tanto, que interpretar su afirmación de que "el nacimiento del lector se paga con la muerte del Autor [sic mayúscula]" (1994: 71) como una correlación dinámica entre ambos, en el sentido de que la mayor presencia de uno en el texto disminuye la del otro, pero sin que el autor llegue a desaparecer por completo. Esto supondría ciertas limitaciones a la concepción de la lectura como el "acto máximo de liberación del sujeto" de Barthes, quien, como señala Nogales Baena, da a entender que "es gracias al carácter intertextual de todo texto, precisamente, por el que el lector puede 'navegar a la deriva' por el 'texto infinito' de la cultura, dejándose llevar por su propia experiencia lectora" (2017: 36). Sin pretender hacer una teoría universal al respecto y volviendo al caso concreto sobre el que versa este trabajo, la libertad del lector para desplazarse libremente por el discurso de Auxilio Lacouture identificando secuencias textuales que remitan a la novela de Fernando del Paso queda sujeta a ciertas restricciones, en el sentido de que es el autor de Los detectives salvajes quien decide poner o no en marcha el dispositivo que anuncia la relación entre ambas novelas; pero hay que precisar que este 
anuncio funcionará solo para el grupo de lectores que haya leído previamente Noticias del Imperio y la recuerden. A partir de este gesto del autor, el lector predispuesto a nuevas llamadas de atención se sentirá libre para establecer futuras conexiones en función del grado de conocimiento de la obra aludida y de otros materiales culturales a su alcance. Dichas conexiones resultarán congruentes para él y obtendrá con ellas una lectura diferente a la de otros lectores. Esto nos llevaría a admitir que "hay autor, pero no como principio que garantiza la verdad, sino como su apoyatura, como el inevitable acompañante auténticamente sujeto, agarrado a una verdad por revelarse" (Topuzian 2014: 155), y a quien el lector necesita volver periódicamente como referente.

Lo que parece desprenderse de lo expuesto hasta ahora con respecto al libre recorrido del lector por un texto es que es el autor quien, de algún modo, marca la casilla de salida para su lectura. En este sentido, Eco no tiene problema en admitir que mientras se está escribiendo "hay un diálogo entre el autor y el primer lector modelo", aunque, una vez que la obra está terminada, lo que se dé sea una relación entre el texto y sus lectores de la que el autor ya no participa (1984: 28). Por tanto, hemos de pensar que, al menos durante la escritura de la declaración de Auxilio Lacouture, su autor tuvo la intención de comunicarse con un lector conocedor del primer capítulo de Noticias del Imperio, aunque el dispositivo puesto en marcha para lograrlo sea tan vago que para muchos de ellos podría haber pasado inadvertido.

\section{Las marcas de intertextualidad en el testimonio de Auxilio Lacouture que remiten al discurso de Carlota de México}

Es preciso recordar que la primera señal o marca de correspondencia entre el capítulo cuarto de la segunda parte de Los detectives salvajes y el primero de Noticias del Imperio aparece con anterioridad a la lectura misma del cuerpo del texto, ya que se basa en una similitud en la estructura del título de ambos: "Castillo de Bouchout. 1927" y "Auxilio Lacouture, Facultad de Filosofía y Letras, UNAM, México DF, diciembre de 1976". Es decir, dichos epígrafes informan del lugar y año en que sus protagonistas, Carlota y Auxilio, recuerdan ciertos acontecimientos de su vida pasada en sendos discursos construidos con párrafos que parecen infinitos. El paralelismo en la estructura sintáctica de las oraciones de ambos textos, encabezadas en su mayoría por el pronombre yo, proporciona un segundo dispositivo de aviso al lector; esta vez, de tipo acústico conseguido gracias a la musicalidad que produce la repetición de un esquema 
sintáctico sujeto + verbo + objeto o, en su defecto, sujeto + verbo copulativo + atributo, en el que el último elemento oracional se alarga de forma progresiva mediante oraciones subordinadas que hacen avanzar el discurso de manera morosa:

Yo soy la madre de la poesía mexicana. Yo conozco a todos los poetas y todos los poetas me conocen a mí. Yo conocí a Arturo Belano cuando él tenía dieciséis años y era un niño tímido y no sabía beber. Yo soy uruguaya, de Montevideo, pero un día llegué a México sin saber muy bien por qué, ni a qué, ni cómo, ni cuándo [...]. (Bolaño 1998: 191)

y:

Yo soy María Carlota de Bélgica, Emperatriz de México y de América. Yo soy María Carlota Amalia, prima de la Reina Victoria de Inglaterra, Gran Maestre de la Cruz de San Carlos y Virreina de las provincias del Lombardo Véneto acogidas por la piedad y la clemencia austríacas bajo las alas del águila bicéfala de la Casa de Habsburgo. Yo soy María Carlota Amalia Victoria, hija de Leopoldo Príncipe de Sajonia-Coburgo y el Rey de Bélgica, a quien llamaban el Néstor de los gobernantes y que me sentaba en sus piernas, acariciaba mis cabellos castaños y me decía que yo era la pequeña sílfide del palacio de Laeken [...]. (Del Paso 1994: 9)

El carácter más elusivo que alusivo de las marcas intertextuales proporcionadas por Bolaño podría interpretase como un intento por parte del autor de retar al lector conocedor de la novela de Del Paso a descubrir dónde está la clave que permite leer las dos obras en paralelo, ya que es posible que, incluso para algunos de estos lectores, la secuencia rítmica que permite conectar ambos textos pase desapercibida, de igual manera que solo los lectores muy familiarizados con Noticias del Imperio podrán apreciar el ritmo del pareado aliterativo que forman los nombres de León Felipe y de Luis Felipe sonando en las voces de Auxilio Lacouture y de Carlota de Bélgica, respectivamente, ligados, además, en la vida real por la experiencia del exilio:

Yo ya no me acuerdo ni de las fechas ni de los peregrinajes, lo único que sé es que llegué a México y ya no me volví a marchar. Yo llegué a México cuando aún estaba vivo León Felipe. (Bolaño 1998: 191)

Yo soy María Carlota Amalia Victoria Clementina, hija de Luisa María de Orleáns, la reina santa de los ojos azules y la nariz borbona que murió de consunción y de tristeza por el exilio y la muerte de Luis Felipe. (Del Paso 1994: 9) 
Además, un lector informado de los avatares personales de León Felipe es posible que llegue a establecer una conexión con el destronado Luis Felipe por la experiencia compartida del exilio; de igual modo, algún otro lector puede ligar este hecho a la condición de expatriado del propio autor o de la poetisa uruguaya Alcira Soust Scalfo, "el negativo" de Auxilio Lacouture, "una maestra de Durazno que viajó a México y conoció a Bolaño en 1970" (Bajter 2009: 1). Umberto Eco (2002) explica la posibilidad de encontrar en un texto diferentes lecturas de dos maneras distintas. Por una parte, el semiólogo italiano asume el dialogismo como una de las características de la literatura postmoderna y lo relaciona con la "ironía intertextual" y el llamado double coding de Charles Jennk, quien piensa que la obra de arte postmoderna -y pone como ejemplo la arquitectura - va dirigida al mismo tiempo a un público minoritario y a otro de masas (Eco 2002: 225). Su traslación al campo de la literatura supone la existencia de tres tipos de lectores: uno que rechaza el conglomerado de contenidos cultos y populares, otro que se siente a gusto con la mezcla y la disfruta y un tercero que la disfruta también, pero que no capta las referencias cultas. En este caso, el lector que advierte que el monólogo de Auxilio Lacouture es un artificio literario que remite a otros textos sería del segundo tipo. Es aquí, continúa Eco, donde entra en juego la estrategia de la ironía intertextual por virtud de la cual "el que entiende el guiño establece una relación privilegiada con el texto (o la voz narrativa)" y quien no lo advierta tiene la opción de proseguir la lectura -como un relato más de los encuentros de los personajes que conocieron a Belano y Lima-, pero sin saborear el cambio de significado que la referencia intertextual introduce en el texto y "su afectuosa ironía" (Eco 2002: 229).

Con respecto a los lectores que perciben haber superado el reto de descubrir el mecanismo de intertextualidad puesto en marcha por Bolaño y que aceptan el de leer el texto con la vista puesta en Noticias del Imperio, se sentirán legitimados para realizar conexiones cada vez más arriesgadas con elementos culturales que, en ocasiones, pueden situarse fuera de ambos textos, pero que sirven para conectarlos. Así, por ejemplo, a aquellos que estén familiarizados con la historia de las casas reinantes europeas en el siglo XIX y al mismo tiempo con la literatura universal de ese mismo siglo les será posible establecer una relación dialógica entre la nómina de príncipes europeos mencionados por Carlota y la de los poetas de Auxilio Lacouture, salpicadas ambas de expatriados, algo que podría interpretarse como otro guiño intertextual del autor mediante el recurso de travestir a unos personajes en otros. De este modo, mientras que en el testimonio de una aparecen los nombres de los poetas españoles republicanos León Felipe y Pedro Garfías, del griego Giorgios Seferis, de los americanos T. S. Elliot y Ezra 
Pound, de la poetisa costarricense Eunice Odio y el de la salvadoreña Lilián Serpas, en el discurso de la otra lo hacen los nombres y los títulos del Almanaque del Gotha, Victoria de Inglaterra, Leopoldo de Sajonia-Coburgo, Luisa María de Orleáns, Luis Felipe rey de los franceses, el Príncipe Joinville, el conde de París, el duque de Brabante, el conde de Flandes y, el esposo de Carlota, Maximiliano de Austria, "el primer descendiente de los Reyes Católicos Fernando e Isabel que cruzó el mar océano y pisó las tierras de América" (Del Paso 1994: 10).

Hasta aquí, el vínculo intertextual del parlamento de Auxilio Lacouture se ha referido principalmente al capítulo primero de Noticias del Imperio. No obstante, la autoproclamación de Auxilio como "madre de la poesía mexicana", que conoce a todos los poetas y que todos la conocen a ella, remite a otros pasajes de la novela, así como a una polémica maternidad de Carlota fruto de sus relaciones con el coronel Van der Smissen, que no queda clara en la novela (Del Paso 1994: 902), pero que goza de cierta credibilidad (Haslip 1971: 506-507), aunque la emperatriz lo niegue en el capítulo veintitrés, en el que se declara, en cambio, madre de todos los mexicanos:

\footnotetext{
Yo soy mamá Carlota [...] Ellos los mejicanos me hicieron su madre y yo los hice mis hijos. Yo soy mamá Carlota, madre de todos los indios y todos los mestizos, madre de todos los blancos, los negros y los saltapatrases. Yo soy mamá Carlota, madre de Cuauhtémoc y la Malinche, de Manuel Hidalgo y Benito Juárez, de Sor Juana y de Emiliano Zapata. (Del Paso 1994: 910)
}

Lo que relaciona en este caso la novela de Bolaño con la de Del Paso no es la inclusión en la del primero de fragmentos más o menos reconocibles por el lector informado en la del segundo, sino el uso de la parodia para situar a su personaje al lado del de Carlota en el momento de perder el favor de su pueblo, tal y como lo recogen las coplas de "Adiós, Mamá Carlota", que, a su vez, son una adaptación paródica de la canción "Adiós, oh, patria mía", de Ignacio Rodríguez Galván (Ramírez Gil 2016: 301), atribuidas al general republicano Riva Palacio, y que empezaron a correr de boca en boca cuando se supo que la reina y los soldados franceses abandonaban México (Véjar Pérez-Rubio 2009: 22-23):

\footnotetext{
[...] Alegre el marinero

con voz pausada canta, y el ancla ya levanta con extraño rumor.
} 
La nave va en los mares

botando cual pelota.

Adiós, mamá Carlota;

adiós, mi tierno amor.

Según cuenta Del Paso en su novela, la emperatriz habría escuchado estas coplas cerca del Paso del Machaco cantada a lo lejos por unos guerrilleros juaristas (Del Paso 1994: 629). Pero la canción contaba, además, con una versión en la que se mencionaba de manera expresa que la causa de la marcha de Carlota era su controvertido embarazo: "Adiós mamá Carlota, la gente se alborota por verte tan gordota" (Martínez Belli 2018: 20). El uso de los recursos de la ironía y de la polémica - propios ambos de la literatura postmoderna- para abordar el tema de la maternidad sirve para unir a estos dos personajes. Asimismo, para un lector informado, o que desee estarlo, la vuelta obligada de Carlota a Europa remitiría a la de Alcira Soust Scalfo (el trasunto del personaje de Auxilio) a Uruguay en la época en la que, como relata Bajter, pierde el cubículo de la planta octava del edificio de la UNAM en el que se alojaba y comienza su deterioro físico y mental, viviendo de la caridad de los amigos. Es entonces cuando en alguna ocasión tiene que escuchar que alguien le diga "con impertinencia, que regrese con los tupamaros", hasta que algunos miembros de la Facultad de Filosofía le pagaron un pasaje de avión de regreso a casa: "se trata de una deportación muy amistosa, atípica. El 30 de junio de 1988, sobre el avión, Alcira llora a gritos" (2009: 2).

La ironía intertextual, como se ha visto, consigue reunir en un mismo texto a las dos heroínas de la ficción novelesca con sus correspondientes alter ego de la vida real. Pero va más allá de esto, porque es capaz de fundir a Auxilio Lacouture y a Carlota de México en una única figura literaria en la que, además, cada lector puede proyectar materiales de cosecha propia; por lo que su delimitación como personaje resulta problemática. Esta indeterminación de Auxilio Lacouture contrastaría en principio con la sucesión de afirmaciones sobre sí misma precedidas por el pronombre de primera persona vertidas en su discurso, pero que, a la larga, terminan por perder sus cualidades definitorias, pues un yo que se segmenta, prolongándose de manera indefinida, acaba por vaciarse de contenido. Mékouar-Hertzberg se ha referido a esta estrategia de desintegración del yo, presente en los relatos de las mujeres, como la "escritura del yo imposible", un tipo de narraciones en las que lo que se impone "es un dédalo de imágenes pulverizando la presencia del yo inicial: un yo presente en 
tanto que sustituido por una retahíla de imágenes; un yo diluido en una especie de arborescencia, desparramándose por las múltiples sendas del laberinto" (2015: 25).

Esta indeterminación del yo en el discurso de Auxilio Lacouture, manifiesta en el nivel sintáctico de manera paradójica por medio de sucesivas repeticiones, no es más que el reflejo de la dificultad para caracterizarla en el nivel semántico, lo que la convierte de facto, de acuerdo con Fischer-Lichte, en un personaje propio de la postmodernidad literaria, ya que uno de los rasgos característicos de los que aparecen en los textos postmodernos está relacionado con "la disolución del yo y de sus fronteras", puesto que el yo, y cita a Ihab Hassan, "es en realidad un lugar vacío en el que muchos yos se unen y se separan" (Fischer-Lichte 1994: 51-53), lo mismo que en el de Auxilio Lacouture se incorporan para disgregarse el de Alcira Soust y el de Carlota de Bélgica. Y es que, de no ser por las aportaciones de estas dos figuras al personaje de Auxilio, su breve aparición en medio de la amplia nómina de los que circulan por la segunda parte de Los detectives salvajes dejaría al lector con la impresión de que el suyo ha sido dibujado con una serie de trazos borrosos: se sabe que es uruguaya y que un día llegó a México “sin saber muy bien por qué, ni a qué, ni cómo, ni cuándo" (vide supra), donde trabó conocimiento con el mundo académico e intelectual, pero apenas si tenemos una idea clara de qué y cómo vive. Ella misma se identifica con una hormiguita, una cigarra, un murciélago, un duende y un hada; saltando de un ser a otro, como si le costara decidirse con cuál se queda.

En cualquier caso, la imagen que ha terminado por imponerse de Auxilio Lacouture es la de su encierro en los baños de la UNAM la noche de la matanza de Tlatelolco. Aquí, es el lector quien tiene que decidir si se queda con la versión heroica del personaje o con la esperpéntica:

Yo estaba en la Facultad cuando el ejército violó la Autónoma y entró en el campus a detener o a matar a todo el mundo. No, en la Universidad no hubo muertos. Fue en Tlatelolco. ¡Ese nombre que se quede en nuestra memoria para siempre! Pero yo estaba en la Facultad cuando el ejército y los granaderos entraron y arrearon con toda la gente. Cosa más increíble. Yo estaba en el baño, en los baños de una de las plantas de la Facultad, la cuarta, creo, no puedo precisarlo, y estaba sentada en el wáter, con las polleras arremangadas. (Bolaño 1998: 192) 


\section{La ausencia de citas concretas en el testimonio de Auxilio Lacouture}

De acuerdo con Rubin Suleiman, si hay algo en lo que todos los teóricos parecen estar de acuerdo es en que la "modernidad", término con el que de manera intencionada pretende abarcar tanto lo que unos entienden como modernismo y otros, como postmodernismo, "se caracteriza por un sentido de crisis cultural, que incluye -tal vez y, ante todo- un sentido de crisis en lo concerniente al lenguaje" (Rubin Suleiman 1993: 89). Esto abre los textos a múltiples interpretaciones, de tal modo que el lector del relato de Auxilio Lacouture recordando su encierro en los baños de la UNAM la noche de la matanza de Tlatelolco puede remitir tanto a los testimonios en primera persona de la novela de Elena Poniatowska $L a$ noche de Tlatelolco. Testimonios de historia oral (1971) como al de Carlota de Bélgica confinada en su Castillo de Bouchout rememorando otras matanzas que tuvieron lugar durante su reclusión, como la del archiduque Francisco Fernando y su esposa Sofía Chotek en Sarajevo el veintiocho de junio de mil novecientos catorce, como también las que vinieron a continuación de "medio millón de hombres a orillas del Marne y un millón en Verdún y cuatrocientos mil en el fango de Passchendaele" (Del Paso 1994: 744) y otras más que habían ocurrido antes; entre ellas, la de su marido, el emperador Maximiliano, en el Cerro de las Campanas, sobre cuyo ataúd comenzó a nevar cuando se lo llevaban de Veracruz a Triste, igual que "nevó sobre los muertos en la batalla de Celaya, y sobre los cadáveres de los armenios masacrados en Constantinopla", lo mismo que "ha nevado durante sesenta" para una muerta en vida como Carlota sepultada en su castillo de Bélgica. Se ha visto ya que ninguna de las referencias a otras obras señaladas anteriormente es mencionada de manera expresa en el texto por Bolaño. Tampoco en este último extracto de Noticias del Imperio lo hace de Del Paso, aunque la alusión al relato "Los Muertos" de Dubliners (1914) de Joyce es evidente:

Su alma caía lenta en la duermevela al oír caer la nieve leve sobre el universo y caer leve la nieve, como el descenso de su último ocaso, sobre todos los vivos y sobre los muertos. (Traducción de G. Cabrera Infante). (García Tortosa 1994: 20)

Puede afirmarse, entonces, que, en los último textos analizados, lo que se muestra es una clase de intertextualidad que no descansa en citas concretas, ya que, de acuerdo con Pavlicic, la obra postmoderna "no establece una relación con lo individual, sino con lo general, no se vincula a un texto concreto, sino a un grupo de textos; la obra posmoderna remite así a todo 
un género o a toda una época, o a toda una convención literaria” (2007: 91), como pueden ser, en este caso, la novela testimonial, el género periodístico o la crónica histórica.

Pero la imagen controvertida de Auxilio Lacouture, "sentada en el wáter" de la torre del edifico de la UNAM, remite, mediante otros recursos de la intertextualidad postmoderna citados por Pavlicic, como la polémica, la parodia y el travestismo (2007: 92), a la no menos controvertida de la emperatriz defecando en su bacinilla delante de sus doncellas para que no se comiera su heces (Del Paso 1994: 334), pero también al arquetipo de la reina loca confinada en un castillo, del que Carlota de Bélgica es su mejor representante (Gil Jacinto 2016), aunque ella diga que no, que "loca, Juana la Loca que se cagaba en la cama" (Del Paso 1994: 901). De igual modo, el prototipo de la reina demente en su castillo remite al de la loca del ático y al ensayo La loca del desván de Gilbert y Gubar, cuyo título, confiesan en su prólogo, es una clara alusión a Jane Eyre (1847), la novela de Charlotte Brontë (1998: 12), que, a su vez, para un lector informado remite a la recuela de Jean Rhys, Ancho mar de los Sargazos (1966).

Precisamente, este tipo de mención directa de Gilbert y Gubar al origen del título de su libro y el reconocimiento explícito de Jean Rhys de la fuente de inspiración para su novela son la clase de referencias directas que no están presentes en el tipo de intertextualidad que practica Bolaño y, como se ha visto con el ejemplo de Dubliners, también Del Paso. En el caso de la autora de Ancho mar de los Sargazos, existe una serie de cartas publicadas (Raisking 1999) en la que da cuenta del proceso de creación de su novela, como en esta de marzo de 1965 al editor de Rocket House:

Dear Mr. Wyndham,

This is to tell you something about de novel I am trying to write — provisional title "The first. Mrs. Rochester"- . I mean, of course, de mad woman in "Jane Eyre" [...] it might be possible to unhitch the whole thing from Charlotte Brontë's novel, but, I don't want to do that. It is that particular mad Creole I want to write about [...]. (Raisking 1999: 135)

En cualquier caso, la información de que Jean Rhys tomó el personaje de Bertha Manson de Jane Eyre para crear el suyo de la criolla Antoinette Cosway en Ancho mar de los Sargazos está disponible en la contraportada de prácticamente todas las ediciones de la novela. A través de esta advertencia al lector, la autora establece con este un acuerdo tácito por el que se va a contar la historia de la 
señora Rochester antes de su llegada a los páramos ingleses. Bolaño, en cambio, no establece este tipo de compromiso con sus lectores; por lo que la vinculación que estos realicen entre el personaje de Auxilio Lacouture y Carlota de México tendrá siempre un cierto grado de incertidumbre, pero ya se ha visto que esta se inserta también en la intertextualidad postmoderna.

\section{Conclusiones}

El nivel de incertidumbre presente en la literatura postmoderna no obsta para que podamos extraer una serie de conclusiones con respecto al dialogismo entre Los detectives salvajes y Noticias del Imperio, sobre todo en lo concerniente a los capítulos cuatro de la segunda parte y al uno, respectivamente. La correspondencia más evidente entre ambos textos se observa en el plano sintáctico y tiene que ver con la extensión de los párrafos, o del párrafo en el caso del de Bolaño, pues uno solo es suficiente para ocupar las diez páginas del capítulo, en claro desafío, quizás, a los párrafos de Del Paso, que suelen ocupar alrededor de una página. No obstante, existen diferencias estilísticas entre ambos autores, ya que el primero tiende al uso de la yuxtaposición y de la coordinación de todo tipo - copulativa, disyuntiva, adversativa, distributiva y explicativa-, mientras que el segundo prefiere largas oraciones subordinadas en las que intercala numerosos elementos yuxtapuestos, aunque el efecto de acumulación y de ruptura a la vez -por las necesarias pausas para respirar- alcanzado en estos dos textos sea el mismo. Pero la marca de estilo más característica del texto de Del Paso presente en el de Bolaño es el uso anafórico del pronombre yo, puesto en boca de Carlota únicamente en el primer párrafo, mientras que el personaje de Auxilio lo sigue repitiendo a lo largo de todo el capítulo con una intencionalidad manifiestamente paródica.

En cuanto al plano semántico, el paralelismo entre ambos textos aparece en el tratamiento de temas como el exilio, la situación política de México, la pérdida de la realidad de las dos mujeres o el confinamiento. Ahora bien, Bolaño los aborda recurriendo a una serie de estrategias propias del postmodernismo literario, entre las que se encuentran las exageraciones, la ironía, el doble código, el travestismo, la parodia, la ruptura del yo o el pastiche, y con las que consigue crear un personaje en el que son reconocibles fragmentos de personajes reales, de ficción y de arquetipos culturales.

Tras estas afirmaciones no cabe más que hacer otra, y es que el testimonio de Auxilio Lacouture en Los detectives salvajes remite al de Carlota de México 
en el capítulo primero de Noticias del Imperio. Tanto la estructura narrativa como la selección de los temas efectuadas por Bolaño son una inequívoca llamada de atención a los lectores que han leído previamente la novela de Del Paso, a quien mencionará por su nombre, en otro guiño de complicidad, en dos ocasiones más adelante. Por lo tanto, no parece plausible admitir, al menos en este caso, que el autor, tras poner en marcha el dispositivo que avisa del juego intertextual, desaparezca y ceda todo el protagonismo al lector informado, sino que le va a ir dejando nuevas pistas por si la primera y más evidente le hubiera pasado inadvertida. Además, el autor sigue estando presente en la medida en que parte de la pluralidad de significados que adquiere el texto para el lector cómplice de los mecanismos de intertextualidad puestos en marcha se completan con datos de la biografía de Bolaño, como los referidos a su exilio en México o su amistad con Alcira Soust, inspiradora de Auxilio Lacouture, y esta, a su vez, alter ego del propio Bolaño.

En cuanto a quienes no hayan captado la ironía intertextual, habrán podido hacer, igualmente, una lectura personal de la novela y disfrutarla de acuerdo con sus intereses y gustos literarios, ya que el hecho de no conectar el discurso de Auxilio Lacouture con el de Carlota de México en Noticias del Imperio no altera el sentido ni la funcionalidad de su testimonio en la serie de testimonios de otros personajes que conforman la estructura de la segunda parte de Los detectives salvajes, de igual modo que no altera de manera sustancial su comprensión general acerca de los hechos narrados en la novela.

\section{Bibliografía}

BAJTER, I. (2009). "Tras las huellas de Alcira Soust". Brecha. Uruguay, 9 de enero de 2009: 1-4. <https://ia800700.us.archive.org/35/items/ LaLupaDedicadaAAlcira/La_Lupa_dedicada_a_Alcira.pdf $>$. (Acceso 10 marzo 2020)

BARTHES, R. 1994 (1968). "La muerte del autor" en El susurro del lenguaje. Más allá de la palabra y la escritura. (Trad. C. Fernández Medrano). Barcelona: Ediciones Paidós: 65-71.

BOLAÑO, R. (1998). Los detectives salvajes. Barcelona: Anagrama.

BRONTË, Ch. 1962 (1847). Jane Eyre. Middlesex, Harmondsworth: Penguin Books. ECO, U. (1984). "Apostilla a El nombre de la rosa". Anàlisi: quaderns de comunicació $i$ cultura 9: 5-32. <https://www.raco.cat/index.php/Analisi/ article/view/41264/88267>. (Acceso 10 mayo 2020) 
ECO, U. (2002). Sobre literatura. Barcelona: RqueR. Enciclopedia de la Literatura en México. Fundación para las letras mexicanas. Secretaría de cultura.

FISCHER-LICHTE, E. (1994). "El postmoderno: ¿continuación o fin del moderno?”. Criterios 31: 49-64. <https://vdocuments.site/reader/full/fischer-lichte-elposmoderno-continuacion-o-fin-del-moderno $>$. (Acceso 9 mayo 2020).

FUENTE, C. (1958). La región más transparente. México: Fondo de Cultura Económica.

GARCÍA TORTOSA, F. (1994). "Las traducciones de Joyce al español" en Joyce en España. IV Encuentros de la Asociación Española James Joyce 1. (Coords. Antonio Raúl de Toro Santos y Francisco García Tortosa). A Coruña: Universidade. Servizo de Publicacións: 19-29. $<$ https://idus.us.es/ bitstream/handle/11441/18004/file_1.pdf?sequence=1\&isAllowed=y $>$. (Acceso 28 mayo 2020)

GENETTE, G. (1989). Palimpsestos. Madrid: Taurus. Traducción de Fernández Prieto, C.

GILBERT, S. M. y GUBAR, S. 1998 (1979). La loca del desván: la escritora y la imaginación literaria del siglo XIX. Valencia: Universitat de Valencia. Traducción de Martínez Gimeno, C.

GIL JACINTO, F. J. (1916). "Carlota eran todas. Las representaciones de la reina loca en el castillo". Revista internacional de culturas y literaturas 1: 1-19. <http://www.escritorasyescrituras.com/wp-content/archivos/carlota. pdf $>$. (Acceso 12 febrero 2020)

GÓMEZ GONZÁLEZ, B. I. de y CASTILLO PERILLA, M. (1998). "Hacia una teoría de la intertextualidad". Folios 8: 31-34. <https://dialnet.unirioja.es/ servlet/articulo?codigo $=6043462>$. (Acceso 3 abril 2020)

HASLIP, J. (1971). The Crown of Mexico. Maximilian and His Empress Carlota. New York, Chicago, San Francisco: Holt, Rinehart and Winston.

JOYCE, J. (1914). Dubliners. London: Grant Richard.

LEAL, A. (2019). "Con-formación de la mercancía-Bolaño. La vida editorial de Roberto Bolaño según Jorge Herralde". Poligramas, 49: 41-61. <http:// poligramas.univalle.edu.co/index.php/poligramas/article/view/8677>. (Acceso 10 junio 20)

MARTÍNEZ BELLI, L. (2018). Locura imperial. Barcelona: Espasa.

MARTÍNEZ FERNÁNDEZ, J. E. (2001). La intertextualidad literaria: Base teórica y práctica textual. Madrid: Cátedra.

MÉKOUAR-HERTZBERG, N. (2015). "Escritura del "yo" imposible" Ámbitos. Revista de Estudios de Ciencias Sociales y Humanidades 33: 23-29. 
$<$ https://helvia.uco.es/bitstream/handle/10396/13134/Ambitos_33_03. pdf? sequence $=1$ \&isAllowed $=\mathrm{y}>$. (Acceso 20 abril 2020).

MONTES DONCEL, R. E. y REBOLLO ÁVALOS, M. J. (2006). "La intertextualidad (1967-2007). El largo periplo de un término teórico". Alfinge: Revista de filología 18: 157-180. <https://dialnet.unirioja.es/servlet/ articulo? codigo $=2574343>$. (Acceso 1 mayo 2020)

MORA VALCÁRCEL, C. de. (2015). "El canon literario mexicano en Los detectives salvajes". Romanische Studien 1 (1): 33-52. <http://hdl.handle. net $/ 11441 / 55277>$. (Acceso 30 junio 2020)

NOGALES BAENA, J. L. (2017). La intertextualidad en la narrativa breve de Sergio Pitol. (Tesis doctoral inédita). Sevilla: Universidad de Sevilla. $<$ https://hdl.handle.net/11441/77195>. (Acceso 7 marzo 2020)

PASO, F. del. 1994 (1987). Noticias del Imperio. Barcelona: Plaza y Janés.

PAVLICIC, P. 2007 (1993). "La intertextualidad moderna y posmoderna". Criterios 30: 85-87. (Ed. de Versión de Estudios de Comunicación y Política, 18: 87-113). <https://versionojs.xoc.uam.mx/index.php/version/article/ view/279>. (Acceso 17 julio 2020)

PERTHES, J. (1763-1944). Almanach de Gotha: annuaire généalogique, diplomatique et statistique. Gotha: Casa Justus Perthes.

PONIATOWKA, E. (1971). La noche de Tlatelolco: Testimonios de historia oral. México DF: Ediciones Era.

RAISKIN, J. L. (1999). Wide Sargasso Sea. New York, London: W. W. Norton \& Company.

RAMÍREZ GIL, R. (2016). “El corrido' mexicano y la discriminación” en Simposium Anual Internacional Científico Práctico. Discursología: Metodología, teoría y práctica: 219-295. <https://sites.susu.ru/dmtp/ wp-content/uploads/sites/47/2016/11/10\%D0\%BA-16.11.2016\%D0\% $\mathrm{BF} \% \mathrm{D} 0 \% \mathrm{BE} \% \mathrm{D} 0 \% \mathrm{BB} \% \mathrm{D} 0 \% \mathrm{BD}$.pdf\#page=296>. (Acceso 12 junio 2020)

RHYS, J. (1966). Wide Sargasso Sea. London: Penguin Books.

RIFFATERRE, M. (1979). La Production du texte. Paris: Seuil.

RUBIN SULEIMAN, S. (1993). "El nombrar y la diferencia: reflexiones sobre modernismo versus postmodernismo en la literatura". Criterios 30: 88-103.

TOPUZIAN, M. (2014). "Muerte y resurrección del autor (1963-2005)". Filología 154 (45): 153-155. <https://core.ac.uk/download/pdf/230968571. pdf $>$. (Acceso 23 junio 2020)

VÉJAR PÉREZ-RUBIO, C. (2009). "Adiós, mamá Carlota". Archipiélago. Revista cultural de nuestra América, 66 (17): 21-23. <http://www.revistas. 
unam.mx/index.php/archipielago/article/view/20164>. (Acceso 15 junio 2020)

VICENTE-YAGÜE,M.I.de.(2013). “Fundamentación teórica de la intertextualidad literario-musical como línea de investigación e innovación en Didáctica de la Lengua y la Literatura". Dialogía: revista de lingüistica, literatura y cultura 7: 245-267. <https://dialnet.unirioja.es/servlet/articulo?codigo=4773394>. (Acceso 2 junio 2020) 